\title{
Effects of the Strategic Values on the Performance of Technical Training Institutions in Meru County, Kenya
}

\author{
George Mungiria Muthaa \\ Department of Education, Chuka University, Chuka, Kenya \\ Email: gmuthaa@yahoo.com
}

How to cite this paper: Muthaa, G.M. (2018) Effects of the Strategic Values on the Performance of Technical Training Institutions in Meru County, Kenya. Open Journal of Social Sciences, 6, 1-11. https://doi.org/10.4236/jss.2018.69001

Received: July 10, 2018

Accepted: August 27, 2018

Published: August 30, 2018

Copyright $\odot 2018$ by author and Scientific Research Publishing Inc. This work is licensed under the Creative Commons Attribution International License (CC BY 4.0).

http://creativecommons.org/licenses/by/4.0/

\section{(c) (i) Open Access}

\begin{abstract}
Organizational performance is important in justifying its existence and resources allocation. To enhance performance, strategic values are useful management tools to achieving competitive advantage. For Technical Training Institutions to achieve their core mandate in human resource training, the Government has emphasized on their development and implementation of strategic plans. Technical Training institutions have been operating with strategic plans for at least the last ten years; however no systematic study has been carried out to investigate the influence of their strategic values on the performance of the institutions. The current study sought to investigate the effects of the strategic values on performance in respect to enrolment, resources, quality and efficiency. The study used the cross sectional descriptive survey research design. The study was conducted with the top, middle and lower level management in the three Technical training institutions of Meru County. Questionnaires were used for data collection. Instruments were tested for reliability by use of the Cronbach's alpha and a correlation coefficient of 0.75 was obtained. Data was analyzed by use of both descriptive and inferential statistics and presented by use of tables and figures. The study established that the strategic values had significant influence on the performance of technical training institutional. The introduction of the government policy has a moderating variable improved the model on strategic value. The researcher recommends the alignment of the institutional philosophy to the institutional strategic values which could improve the performance of Technical Training Institutions.
\end{abstract}

\section{Keywords}

Effect, Strategic Values and Performance 


\section{Introduction}

Organizations are developed with the objective of providing service to society. The organizations compete for resources with other sectors of the economy. The continued funding for such organizations can be justified by their performance. However, the environment is complex, turbulent and dynamic [1]. The exigencies in the remote and immediate environment further intensify competition for supplies and markets creating uncertainties that present opportunities, threats and constraints to firms [2]. Corporate strategy is an essential management tool to achieving a firm's performance through strategic initiatives [3]. It's against this backdrop that the concept of strategic plan has become popular as a management's tool not only to steer a firm's survival but also improve performance.

The desire for Strategic plans in Kenya commenced slowly and gradually back in the 1960s but has presently gaining currency and popularity [4]. The public sector finds the concept of strategic plans just as important as in commercial firms and hence Technical Training Institutions in Meru County are required to formulate strategic plans in tandem with the MoE's strategic plan in order to foster the government's agenda to provide trainees with the quality education and training [5]. Strategic plans are expected to positively influence performance by enhancing the financial and non-financial outcomes in the training institutions. This makes the strategic plans a necessary management tool for Technical Training Institutions in Meru County if these institutions are to justify their public financial support and produce graduates that help in meeting the country's development vision.

A number of scholars have argued that there is a positive correlation between strategic planning and performance while others argue that the relationship between planning and performance is inconsistent and thus still debatable [6] [7] [8]. There have been studies on influence of strategic planning on performance in other education sectors. For instance, Mukokho studied the influence of strategic planning on performance of public universities in Kenya, the case of university of Nairobi [9], Gode studied influence of strategic planning on the performance of public secondary schools in Kisumu East [10], Ayieko studied strategic planning practices and performance of manufacturing firms [11]. The above studies recommended for the development of strategic plans to enhance performance in the studied sectors. A study of strategic planning and performance in public secondary schools in Rarienda District indicated the importance of strategy planning in public secondary schools and therefore suggested a replication of the study in different parts of the county and other levels of education [12]. Despite the critical role that the Technical Training Institutions play in human resource training and the concern raised with regards to the quality of graduate, the enrolment levels and resources in these institutions, the sectors seem to have been ignored by researchers which show a knowledge gap that needs to be addressed.

One of the major influences of organizational culture is the organizational 
system of values. If widely held throughout the organization, values will eventually affect the way customers are perceived and treated, the way employees and other contributors are viewed and awarded and the way the future is anticipated and managed. Hence organizational values play a critical role in the success of an organization [13].

Organizational values define the acceptable standards which govern the behaviour of individuals within the organization. Without such values, individuals within the organization will pursue behaviours that are in line with their own individual value systems, which may lead to behaviors that the organization doesn't wish to encourage. Marcoulides and Heck analyzed the relationship between values and performance using data collected from 26 organizations [14]. They proposed a model in which organizational culture was measured using several variables (organizational structure and organizational values) and organizational performance was measured using capital, financial and market indicators. The results of the study showed that the variables used to measure organizational culture had some effect on performance.

Peters and Waterman identified several organizational values which were related to performance and excellence [15]. They studied a group of American firms which were widely recognized as being superior performers in their industries for many years. Their findings indicated that excellent firm's possess distinct and identifiable organizational values which included beliefs about superior quality and services being the best. There is no available literature on the relationship between values and performance of technical training institutions which gives impetus to the current study.

\section{Research Hypotheses}

$\mathrm{H}_{\mathrm{O} 2}$ : There is no effect of the strategic values on the performance of Technical Training Institutions in Meru County.

\section{Research Methodology}

This study employed cross-sectional descriptive survey and correlational designs. Cross-sectional descriptive survey design was appropriate design for this study since the researcher sought to collect data on the existing phenomenon with regard to the variables of this study. The correlational design enabled the researcher to test the relationship between strategic values and performance.

The target population for the study was the 90 members of management in the three Technical Training Institutions in Meru County. All the members of management of the training institutions participated in the study. These included the top management, made up of the Principal, the two deputy Principals, the finance officer and the registrar, the middle level management made up of the heads of departments and the dean of students and the lower level management, made up of the heads of sections.

Primary data was collected by use Questionnaires. Reliability was estimated by Cronbach's alpha. A reliability coefficient of 0.75 was obtained which was above 
0.7 considered appropriate for social studies according to [16]. Validity of the instruments was ensured by use of peers in checking the content validity. The researcher personally administered the instruments to the respondents.

The data was analysed using both descriptive and inferential statistics in Statistical Package for Social Sciences (SPSS) Version 12.0 software. Descriptive statistics was used to measure central tendency and dispersion. Pearson's Product Moment Correlation ( $r$ ) was derived to show the nature and strength of the relationships. Adjusted $\mathrm{R}^{2}$ was used to measure the amount of variations in the dependent variable of change explained by the independent variable of the strategic plan. Simple regression analyse was conducted to establish the effect of the independent variable on the dependent variable.

\section{Results and Discussions}

The researcher sought information on the gender of the respondents. This information is shown in Figure 1.

Information in Figure 1 shows that majority (58.1\%) of the respondents were of the male gender. The composition of respondents by gender shows that the institutions involved in the study satisfy the gender for one third representations.

An item was included in the instruments that sought information on the duration that the respondent had served in their current positions. This information is presented in Table 1.

Information in Table 1 indicates that $49.2 \%$ of the respondents had served in their current position for over five years whereas $17.7 \%$ of the respondents had served for less than two years in their current positions. Having $49.2 \%$ of the respondents who had served in the institutions for more than five years means that respondents have experienced the planning and implementation of the strategic plans which was critical in the current study.

The researcher sought information on the academic qualifications of the respondents. The responses are presented in Figure 2.

Information in Figure 2 shows that $42.7 \%$ of the respondents had a bachelor's qualification while $32.3 \%$ had a diploma qualification.

The researcher sought information on whether the respondents were trained on strategic planning. This information is shown in Figure 3.

Table 1. Duration served in the current position.

\begin{tabular}{ccc}
\hline Duration of service & Frequency & Percent \\
\hline$<2$ years & 22 & 17.7 \\
$2-3$ years & 20 & 16.1 \\
$4-5$ years & 19 & 15.3 \\
$>5$ years & 61 & 49.2 \\
Total & 122 & 98.4 \\
\hline
\end{tabular}




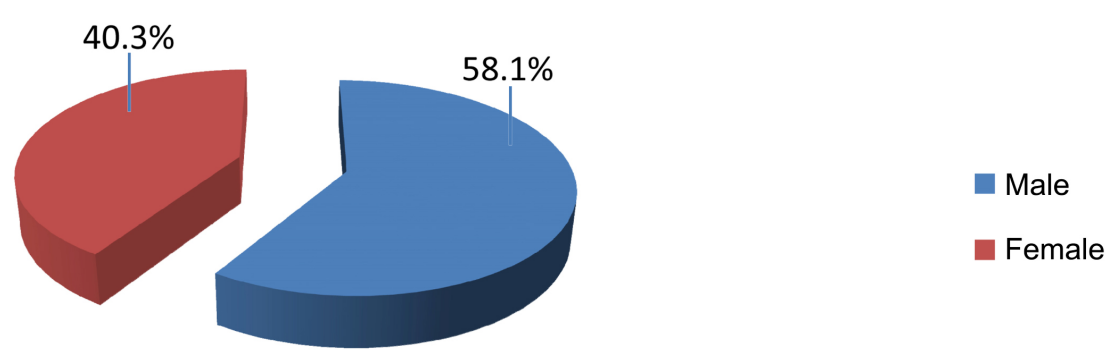

Figure 1. Gender of the respondents.

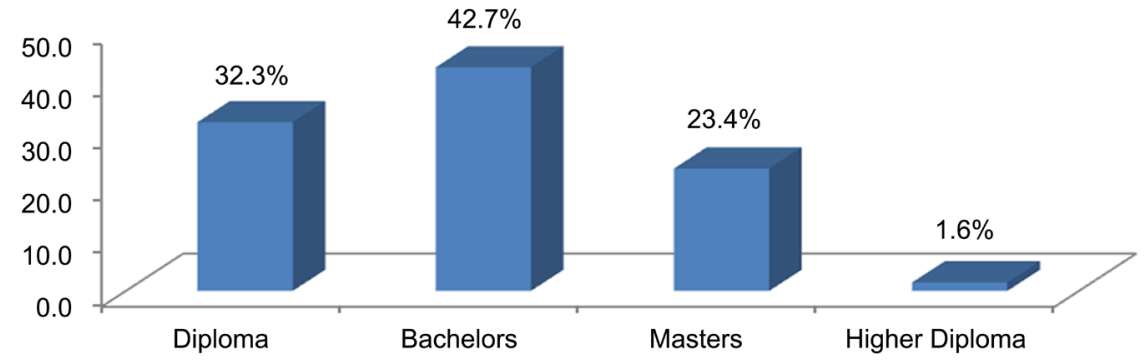

Figure 2. Academic qualifications of respondents.
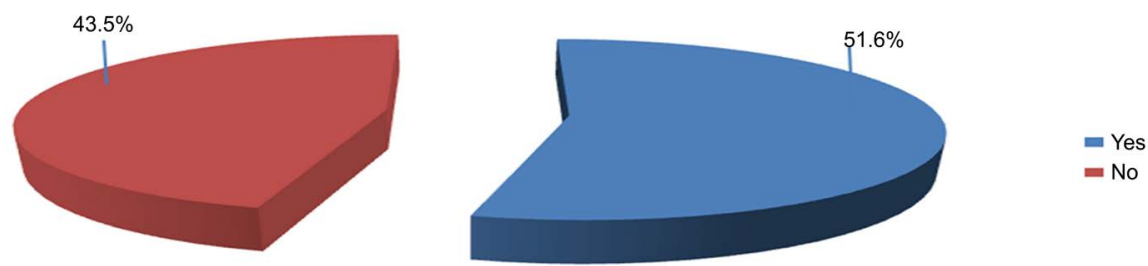

Figure 3. Training on strategic planning.

Information in Figure 3 shows that majority (51.6\%) of the respondents had some training in strategic management whereas $43.5 \%$ indicated that they had no training in strategic management. The fraction of $43.5 \%$ of the respondents who have no training in strategic management should be an issue of concern if planning and implementation of the strategic plans has to be effective.

The researcher further sought information from the respondent on their self-rating on competency in strategic planning. This information is shown in Table 2.

Information in Table 2 shows that $35.5 \%$ of the respondents rated themselves as competent while $19.4 \%$ of the respondents held no opinion on their levels of competence in strategic planning. Only $14.5 \%$ of the respondents indicated that they were very competent in strategic planning.

\subsection{Descriptive Statistics}

The researcher sought information on the extent to which the dimensions of the strategic values were in line with the strategic plans of the institutions. The information for this article is presented in Table 3. 
Table 2. Competency level.

\begin{tabular}{ccc}
\hline Responses & Frequency & Percent \\
\hline Very competent & 18 & 14.5 \\
Competent & 44 & 35.5 \\
No Opinion & 24 & 19.4 \\
Incompetent & 1 & 0.8 \\
No response & 37 & 29.8 \\
Total & 124 & 100.0 \\
\hline
\end{tabular}

Table 3. Strategic values.

\begin{tabular}{cccc}
\hline Strategic Values & $\mathrm{N}$ & Mean & Std. Deviation \\
\hline Integrity/Accountability & 122 & 4.06 & 0.565 \\
Collaboration & 118 & 3.89 & 0.725 \\
Customer focus & 124 & 4.18 & 0.527 \\
Commitment & 124 & 4.06 & 0.537 \\
Innovation & 122 & 3.72 & 0.893 \\
Professionalism & 122 & 4.02 & 0.698 \\
Courtesy & 124 & 4.05 & 0.661 \\
Responsibility & 124 & 4.06 & 0.779 \\
Overall mean score & & 4.00 & 0.673 \\
\hline
\end{tabular}

Information in Table 3 yielded an overall mean of 4.00. Customer focus dimension of the strategic values in the strategic plan had the highest mean score (mean score $=4.18, \mathrm{SD}=0.527$ ). This shows that respondents rated the dimension of customer focus has having the highest alignment to the organization strategic values. The dimensions that attained the lowest mean score where innovative (mean score $=3.72, \mathrm{SD}=0.893$ ) and collaboration (mean score $=3.89$, $\mathrm{SD}=0.725)$ in relation to all the other dimensions of the strategic values in the strategic plan. This implies that the perception of the managers on innovations and collaborations has to be emphasized as a necessary condition in the promotion of the institutions' strategic values for the strategic plans.

The researcher sought information on the extent to which the Government policy being a moderator variable impacted on the institutions' strategic plan. This information is shown in Table 4.

Information in Table 4 shows that the government policy impacted to a great extent on the strategic plans. Accountability (mean score $=3.98, \mathrm{SD}=0.966$ ) and Regulatory quality (mean score $=3.97, \mathrm{SD}=0.852$ ) were most important in the institutions strategic plans. Effectiveness (mean score $=3.82, \mathrm{SD}=0.869$ ) and stability (mean score $=3.84, \mathrm{SD}=0.879$ ) were rated least important in the strategic plans.

To achieve the objectives of the study, the researcher sought information on 
Table 4. Government policy.

\begin{tabular}{cccc}
\hline Government Policy & $\mathrm{N}$ & Mean & Std. Deviation \\
\hline Accountability & 122 & 3.98 & 0.966 \\
stability & 120 & 3.84 & 0.879 \\
Effectiveness & 120 & 3.82 & 0.869 \\
Regulatory quality & 122 & 3.97 & 0.852 \\
Rule of law & 122 & 3.95 & 0.822 \\
Control of corruption & 122 & 3.90 & 0.885 \\
Overall mean score & & 3.91 & 0.879 \\
\hline
\end{tabular}

the performance of technical training institutions. Various indicators were used to assess the extent of performance by the Technical Training Institutions. This information is shown in Table 5.

The results in Table 5 reveal four indicators of performance in technical institutions with a mean of above 4.00. Quality (mean score $=4.22, \mathrm{SD}=0.657$ ), quality of skills (mean score $=4.02, \mathrm{SD}=0.643$ ), quality of infrastructure (mean score $=4.01, \mathrm{SD}=0.888$ ) and efficiency (mean score $=4.01, \mathrm{SD}=0.722$ ) were rated most important dimensions of performance in the technical training institutions. Availability of teaching materials (mean score $=3.25, \mathrm{SD}=1.204$ ) was rated least among the various indicators of performance in the technical training institutions.

\subsection{Regression Analysis and Hypotheses Testing}

The hypothesis of the study sought to investigate the relationship between the strategic values and the performance of the training institutions. This information is presented in Table 6.

Results in Table 6 show the relationship between strategic Values and performance. From the model $20.9 \%$ of the variation in performance can be accounted for by the strategic values in the model. The F-statistics of 32.3 (p-value $0.00<0.05)$ indicates that the overall model was statistically significant at $95 \%$ confidence level. The relationship between strategic Values and performance was statistically significant $(t=5.683$, p-value $0.00<0.05)$. This implies that for one unit increase in strategic Values the performance will increase by a factor of 0.557 . The hypothesis that there was no significant relationship between strategic values and performance was not supported in the current study. The predictive regression model can be stated as:

$$
Y=1.558+0.557 X_{2}
$$

where $Y$-Performance, $X_{2}$-Strategic Values, 1.558-Constant, 0. 557-Is the estimate of the expected change in performance, when strategic value is increased by one unit.

These results are in harmony with the findings that Values are the fundamental principles that organizations and people stand for along with the mission and 
Table 5. Performance.

\begin{tabular}{|c|c|c|c|}
\hline & $\mathrm{N}$ & Mean & Std. Deviation \\
\hline Quality & 124 & 4.22 & 0.657 \\
\hline Quality of trainers & 124 & 3.91 & 0.884 \\
\hline Quality of infrastructure & 124 & 4.01 & 0.888 \\
\hline Quality of training tools & 124 & 3.75 & 0.976 \\
\hline Quality of curriculum & 122 & 3.87 & 0.970 \\
\hline Quality of skills & 122 & 4.02 & 0.643 \\
\hline Quality of knowledge & 120 & 3.88 & 0.881 \\
\hline Quality of graduates & 120 & 3.73 & 0.995 \\
\hline Resources & 120 & 3.89 & 0.848 \\
\hline Adequacy of training materials & 120 & 3.61 & 1.079 \\
\hline Infrastructure development & 120 & 3.93 & 0.909 \\
\hline Human resource development & 120 & 3.79 & 1.003 \\
\hline Availability of teaching materials & 120 & 3.25 & 1.204 \\
\hline Workshop tools \& equipment & 116 & 3.66 & 0.961 \\
\hline Enrolment & 118 & 3.77 & 0.861 \\
\hline Students Enrolment & 122 & 3.86 & 0.816 \\
\hline Retention rates & 122 & 3.78 & 0.828 \\
\hline Completion rates & 122 & 3.96 & 0.648 \\
\hline Efficiency & 118 & 4.01 & 0.722 \\
\hline Efficiency of training process & 120 & 3.78 & 0.822 \\
\hline Acquisition of practical skills & 122 & 3.80 & 1.018 \\
\hline Utilization of resources & 121 & 3.83 & 0.886 \\
\hline
\end{tabular}

Table 6. Regression analysis on strategic values and performance.

\begin{tabular}{ccccccc}
\hline & Unstandardized Coefficients & $\begin{array}{c}\text { Standardized } \\
\text { Coefficients }\end{array}$ & t & Sig. \\
\cline { 1 - 4 } & B & Std. Error & Beta & & \\
\hline $\begin{array}{c}\text { (Constant) } \\
\text { strategic Values }\end{array}$ & 1.558 & 0.395 & & 3.946 & 0.000 \\
\hline
\end{tabular}

R square $=20.9 \%$, F-Statistic $=32.3(0.000<0.05)$.

vision, they make an organization unique. Thompson, Strickland \& Gamble have given the meaning of organizational values as "company's values are the beliefs, business principles, and practices that guide the conduct of its business, the pursuit of its strategic vision, and the behaviour of company personnel" [17]. Values relate to such things as treatment of employees and customers, integrity, ethics, innovativeness, emphasis on quality or service, social responsibility, and community citizenship. Values play a critical role in influencing the performance in organizations [18]. 
Table 7. Regression result of the strategic values with government policy.

\begin{tabular}{|c|c|c|c|c|c|c|}
\hline & \multirow[t]{2}{*}{ Model } & \multicolumn{2}{|c|}{ Unstandardized Coefficients } & \multirow{2}{*}{$\begin{array}{c}\text { Standardized } \\
\text { Coefficients } \\
\text { Beta }\end{array}$} & \multirow[t]{2}{*}{$\mathrm{t}$} & \multirow[t]{2}{*}{ Sig. } \\
\hline & & B & Std. Error & & & \\
\hline \multirow{2}{*}{1} & (Constant) & 1.586 & 0.396 & & 4.005 & 0.000 \\
\hline & strategic Values & 0.548 & 0.098 & 0.453 & 5.574 & 0.000 \\
\hline \multirow{3}{*}{2} & (Constant) & 1.344 & 0.378 & & 3.559 & 0.001 \\
\hline & strategic Values & 0.336 & 0.106 & 0.278 & 3.160 & 0.002 \\
\hline & Government Policy & 0.279 & 0.069 & 0.356 & 4.042 & 0.000 \\
\hline
\end{tabular}

1) $\mathrm{R}$ squared $=0.208$, F-statistic $=31.065(0.000) ; 2)$ R squared $=0.302$, F-statistic $=25.686(0.000)$.

The researcher sought information on the implications of the strategic value with the moderator variable of the government policy. This information is shown in Table 7.

The results presented in Table 7 indicate a significant change in the percentage of the variation explained by the interaction of the strategic values and the government policy. The regression results shows a change in $\mathrm{R}^{2}$ when interaction of government policy and strategic values were introduced $(0.208,0.302)$. Results suggest that the variation in the relationship between strategic values and performance of technical training institutions on introduction of the government policy was statistically significant $(0.336,0.279 ; 0.002,0.000)$. This implies that in the presence of the government policy the relationship is enhanced such that the performance is slightly higher. This means that the influence of the strategic values on performance of technical training institutions is substantially altered by the government policy. Based on these results the performance can be predicted as follows:

$$
Y=1.344+0.336 X_{2}+0.279 M
$$

where $Y=$ performance of technical training institutions, $X_{2}=$ Strategic values, $M=$ Government policy.

\section{Conclusion}

Judging from the findings resulting from the data collected for this study, the results reveal some vital facts upon which the conclusions are based. The study showed that strategic values had significant influence on the performance of Technical Training Institutions in Meru County. Customer focus dimension of the strategic values in the strategic plan had the highest influence compared to innovative and the collaboration dimensions which had the lowest mean score in relation to all the other dimensions of the strategic values in the strategic plan.

\section{Recommendations}

Based on the findings of the current study, the researcher made the following recommendations: 
1) There is need for the institutional managers to align the institutional philosophy and the priorities to the institutional strategic values.

2) There is need for innovations and collaborations to be emphasized as a necessary condition in the promotion of the institutions' strategic values thereby enhancing the performance of Technical Training Institutions.

\section{Conflicts of Interest}

The authors declare no conflicts of interest regarding the publication of this paper.

\section{References}

[1] Johnson, S. and Whittington, R. (2008) Exploring Corporate Strategy. 6th Edition, Text and Cas-s Pearson Education Ltd., New Delhi.

[2] Barney, J.B. (2007) Gaining and Sustaining Competitive Advantage. 3rd Edition, Pearson Hall, New Jersey.

[3] Porter, M.E. (1985) Competitive Advantage: Creating and Sustaining Superior Performance. Free Press, New York.

[4] Yabs, J. (2007) Strategic Management Practices in Kenya. Lelax Global Ltd, Nairobi.

[5] Birgen, P. (2007) Strategic Plan: How to Develop a Strategic Plan. Colour Print Ltd, Nairobi.

[6] Cole, G. A. (2004) Management Theory and Practice. 6th Edition, Thomson Learning Bedford Row, London.

[7] Ansoff, I.H. (1990) Implanting Strategic Management. Prentice Hall International Ltd., London.

[8] Thompson, J., Strickland, A. and Gamble, J.E. (2007) Crafting and Executing Strategy: Texts and Readings. The McGraw-Hill, New York.

[9] Muthoko, A.A. (2010) The Influence of Strategic Planning on Performance of Public Universities in Kenya: The Case of University of Nairobi. Unpublished Master's Thesis, University of Nairobi, Nairobi.

[10] Gode, H. (2009) Influence of Strategic Planning on Performance of Public Secondary Schools in Kisumu East. Unpublished MBA Project, University of Nairobi: Nairobi.

[11] Ayieko, M.O. (2009) Strategic Planning Practices and Performance of Large Manufacturing Firms in Kisumu, Kenya. Master of Business Administration, School of Business, University of Nairobi, Nairobi.

[12] Okwako, A.D. (2013) Strategic Planning and Performance of Public Secondary Schools in Rarieda District, Kenya. Masters in Business Administration, University of Nairobi, Nairobi.

[13] Boxx, W.R., Odom, R.Y. and Dunn, M.G. (1991) Organizational Values and Value Congruency and Their Impact on Satisfaction, Commitment and Cohesion: An Empirical Examination within the Public Sector. Public Personnel Management, 20, 195-205. https://doi.org/10.1177/009102609102000207

[14] Marcoulides, G. and Heck, R. (1993) Organizational Culture and Performance: Proposing and Testing a Model. Organization Science, 4, 209-225.

https://doi.org/10.1287/orsc.4.2.209

[15] Peters, T.J. and Waterman, R.H. (1982) In Search of Excellence. Harper Collins, New York. 
[16] Kathuri, N. and Pals, D. (2003) Introduction to Educational Research. Egerton University, Njoro.

[17] Thompson, S. (2005) Strategy Formulation and Implementation. Richard D. Irwin, Boston.

[18] Singh, R.G. and Shah, K. (2012) Directional Strategies and Organizational Performance. https://www.inflibnet.ac.in/ojs/index.php/MC/article/download/3116/2416 